\title{
An outline of $\mathrm{RC}$ buildings performance under tsunami triggered by the East Japan Great Earthquake
}

\author{
C. Cuadra \& S. Ishiyama \\ Department of Architectural and Environment Systems, \\ Akita Prefectural University, Japan
}

\begin{abstract}
The Great East Japan Earthquake on March 11, 2011 is the most powerful known earthquake that has hit Japan with a magnitude 9.0 and epicentre at $129 \mathrm{~km}$ of Sendai city of the Tohoku region (north-east region of Japan). The earthquake triggered a destructive tsunami with run up height of up to 38 meters that mainly affected cities located on the Pacific Ocean coast of the Tohoku region. Reinforced concrete buildings in general resist a tsunami without collapse; however, non-structural elements like panels and ceilings were severely damaged. In this report, the characteristics of the damage and behaviour of RC buildings during the tsunami action is discussed based on the field survey of the damage in selected cities located on the coast of the affected zone. The analysis will allow us to understand the behaviour of these kinds of buildings and also to establish recommendations for their use as places of refuge from a tsunami in places where the natural topography makes it impossible to reach hilltops or other safer places.
\end{abstract}

Keywords: tsunami, RC buildings, East Japan Earthquake, seismic damage.

\section{Introduction}

An earthquake with a magnitude of 9.0 struck the north-east part of Japan (Tohoku region), on 11 March 2011at 14:46 local time. This earthquake is the most powerful known earthquake that has hit Japan with an epicentre at $129 \mathrm{~km}$ of Sendai city of the north-east region of Japan. The earthquake triggered a destructive tsunami with run up height of up to 38 meters. The tsunami affected mainly cities located on the Pacific Ocean coast of Iwate, Miyagi, and 
Fukushima prefectures in the Tohoku region. Wooden structures were destroyed by the tsunami action when the water depth reached 2 meters or more. Steel frame structures and steel trusses that are used mainly for industrial construction suffered heavy damage of walls, ceilings, finishing panels and non-structural elements. In some cases, the failure of these non-structural components produced the failure of structural elements and even the collapse of the structure. Reinforced concrete buildings in general resist the tsunami without collapse; however the non-structural elements like panels and ceilings were severely damaged. In this report, the characteristics of the damage and behaviour of RC buildings during the tsunami action is discussed based on the field survey of the damage in selected cities located on the coast of the affected zone. The analysis will allow us to understand the behaviour of these kinds of buildings and also to establish recommendations for their use to take refuge from tsunami in places where the natural topography makes it impossible to reach hilltops or other safer places.

\section{Characteristics of the earthquake and tsunami}

The Great East Japan Earthquake that occurred on March 11, 2011 (at 14:46) was an inter-plate earthquake which occurred on the boundary between the Pacific Ocean plate and the Continental plate (called American plate). This earthquake is also known as the 2011 off the Pacific Coast of Tohoku Earthquake or the 2011 Tohoku-Pacific Earthquake. The magnitude of the earthquake was reported as being 9.0, which is the highest magnitude ever recorded in Japan. The plane of the rupture or fault extends to about $500 \mathrm{~km}$ in the north-south direction (length) and about $200 \mathrm{~km}$ in the east-west direction (width). Before the main shock, an earthquake of magnitude 7.3 occurred offshore of the Sanriku region on March 9 (see Figure 1 reported by Shimizu Corporation [1]). Many aftershocks occurred, some of them of large magnitude, as is shown in table 1, where five aftershocks were of a magnitude larger than 7. In addition, two large inland earthquakes occurred after the main shock. One occurred on March 12 in the northern part of Nagano Prefecture and was of magnitude 6.7. The other one was the earthquake on March 15 in the eastern part of Shizuoka Prefecture of magnitude 6.4.

Table 1: $\quad$ Main shock and events of large magnitude (larger than 7).

\begin{tabular}{|c|c|c|c|c|}
\hline Event & Date and time & Epicenter & Depth & Magnitude \\
\hline Foreshock & $03 / 09,11: 45$ & $38^{\circ} 19.7^{\prime} \mathrm{N}, 143^{\circ} 16.7^{\prime} \mathrm{E}$ & $8 \mathrm{~km}$ & $\mathrm{Mj} 7.3$ \\
\hline Main & $03 / 11,14: 46$ & $38^{\circ} 06.2^{\prime} \mathrm{N}, 142^{\circ} 51.6^{\prime} \mathrm{E}$ & $24 \mathrm{~km}$ & ${ }^{*} \mathrm{Mw} 9.0$ \\
\hline \multirow{5}{*}{ Aftershocks } & $03 / 11,15: 08$ & $39^{\circ} 50.3^{\prime} \mathrm{N}, 142^{\circ} 46.8^{\prime} \mathrm{E}$ & $32 \mathrm{~km}$ & $\mathrm{Mj} 7.4$ \\
\cline { 2 - 5 } & $03 / 11,15: 15$ & $36^{\circ} 06.5^{\prime} \mathrm{N}, 141^{\circ} 15.9^{\prime} \mathrm{E}$ & $43 \mathrm{~km}$ & $\mathrm{Mj} 7.7$ \\
\cline { 2 - 6 } & $03 / 11,15: 25$ & $37^{\circ} 50.2^{\prime} \mathrm{N}, 144^{\circ} 53.6^{\prime} \mathrm{E}$ & $34 \mathrm{~km}$ & $\mathrm{Mj} 7.5$ \\
\cline { 2 - 6 } & $04 / 07,23: 32$ & $38^{\circ} 12.2^{\prime} \mathrm{N}, 141^{\circ} 55.2^{\prime} \mathrm{E}$ & $66 \mathrm{~km}$ & $\mathrm{Mj} 7.1$ \\
\cline { 2 - 6 } & $04 / 11,17: 16$ & $36^{\circ} 56.7^{\prime} \mathrm{N}, 140^{\circ} 40.3^{\prime} \mathrm{E}$ & $6 \mathrm{~km}$ & $\mathrm{Mj} 7.0$ \\
\hline
\end{tabular}

Mj: Magnitude by Japan Meteorological Agency,

*Mw: Moment Magnitude. 


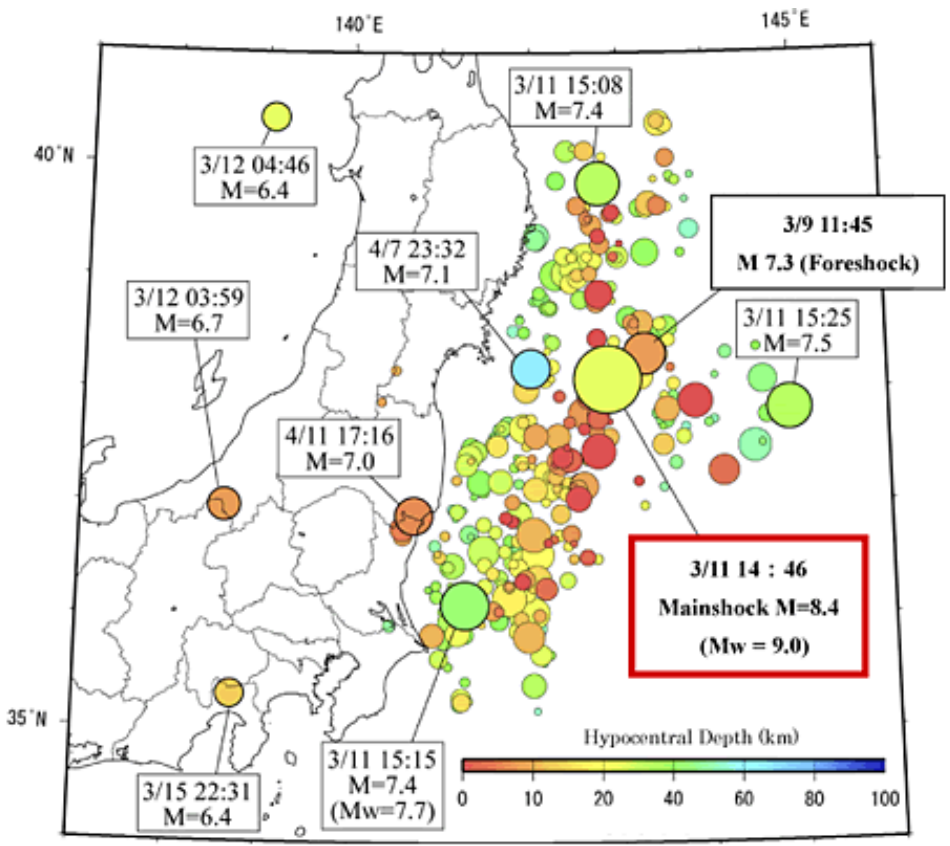

Figure 1: Distribution of epicentres.

The earthquake produced a tsunami that affected a wide area, mainly along the Pacific Ocean coastline from Hokkaido to the Kanto area. Tsunami waves were observed not only in the Hokkaido, Tohoku and Kanto regions, but also in far regions like Tokai, Shikoku and Kyushu regions. In Iwate prefecture and the northern area of Miyagi prefecture, the inundation height and the run-up height of tsunami exceeded 20m. In Figure 2, the distribution of the inundation height and run-up height is observed as is reported by the field survey carried out by the Building Research Institute, Ministry of Construction of Japan [2]. The small circles represent the inundation height which is the height between the water surface at the observation point and the original or normal sea level. The triangles represent the run-up height which is the maximum topographical level reached by the tsunami in reference to the normal sea level. Since both heights are referred to the normal sea level (cero level), it does not mean that these heights are strictly related to the damage on structures. Instead of these heights, the inundation depth which is the height between the water surface at the observation point and the ground level at that point, could be a better value to refer to the damage of buildings. The inundation depth is more directly related to the water pressure which is the cause of the damage on the buildings. The inundation depth varies according to the topographical shape of the ground surface and during the field survey could be estimated from the marks of the tsunami that remains on taller buildings. 

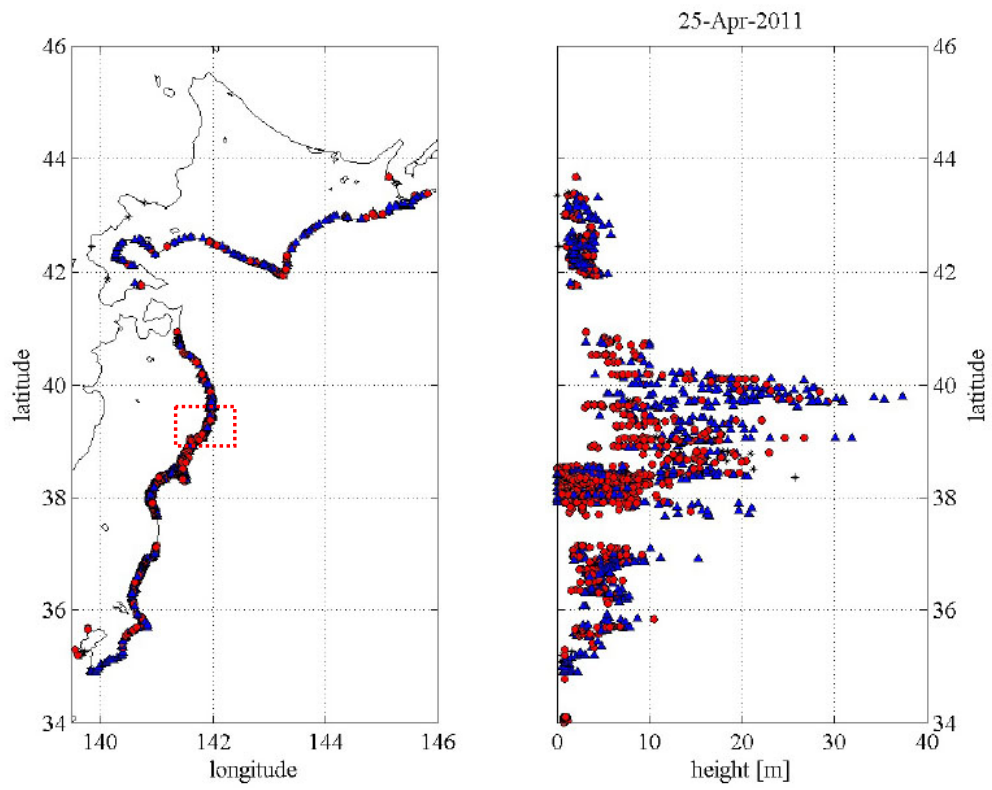

Figure 2: Inundation height and run-up heights.

\section{Damage due to tsunami}

The damage on building structures that were produced by the tsunami are described in this section and especially the damage that occurred on reinforced concrete structures. However, it is necessary to mention that damage is not limited only to building structures. The tsunami also affected many infrastructures like ports, embankments, roads, railroads, oil tanks, and, in its more dramatic damage, affected the nuclear power plant of Fukushima. Environmental damage is also reported, such as the chlorination of agricultural soils, sedimentation of debris near ports, transportation of old industrial and mine residues from the sea bottom to the ground surface, etc.

To compare the damage of reinforced concrete; also damage on wooden structures and steel structures as described as references. In general, the wooden structures collapse when they were attacked by the tsunami. The steel structures remained standing up; however, the finishing walls, ceilings and other non structural elements failed and, in some cases, these failures originated the failure of the main structure. The reinforced concrete structures presented better behaviour and were the structures that in general remained in their original location without structural damage. This can be explained by the high lateral stiffness of the reinforced concrete buildings in comparison with steel structures and wooden structures. The wooden structures have the smaller lateral stiffness and in general were washed up when the tsunami reached or covered the first floor. The relation between the damage and the earthquake resistant characteristics of these three types of structures are summarized in Table 2. 
Table 2: $\quad$ Relation of earthquake resistant forces and damage due to tsunami.

\begin{tabular}{|c|c|c|}
\hline Type of structure & $\begin{array}{c}\text { Earthquake resistant } \\
\text { force for design }\end{array}$ & $\begin{array}{c}\text { Level of } \\
\text { Tsunami damage }\end{array}$ \\
\hline Wooden structure & Low & High \\
\hline Steel structure & Medium & Medium \\
\hline Reinforced concrete & High & Low \\
\hline
\end{tabular}

The sites that were selected for the present survey are shown in Figure 3. This zone is also marked in Figure 2 by a dashed rectangle. The cities of Ofunato, Rikusentakata and Kesennuma were visited to perform the corresponding survey.

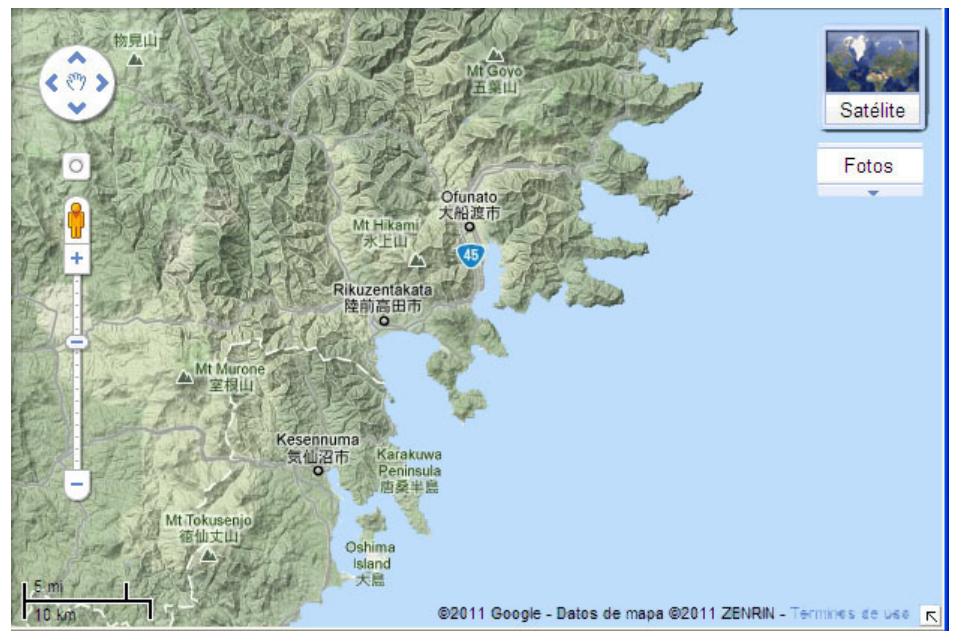

Figure 3: $\quad$ Zone of survey (Google map).

\subsection{Damage on wooden houses}

From damage surveys reported by other authors, it is recognized that in general the wooden houses collapse or present damage due to the tsunami action when the inundation depth is larger than 2 meters. As is presented in Figure 4, the damage on wooden houses is divided into three zones according to the inundation depth. Zone A corresponds to places where the inundation depth is smaller than 2 meters and structural damage is not observed; that is, the wooden houses are safe in this case. Zone B corresponds to a zone where the inundation zone ranges from 2 to 4 meters, and, depending on the structural shape, condition of the structural elements, etc, the houses can suffer from light to severe damage. From the field observation it can be said that when the water level covers the first floor of the wooden house the structures collapse not only due to the lateral force of the water but also due to the water pressure on the ceiling of the first floor causing floating of the upper floors. Zone $\mathrm{C}$ corresponds to a zone where the inundation depth is greater than 4 meters and total collapse of the structure is expected to occur. 


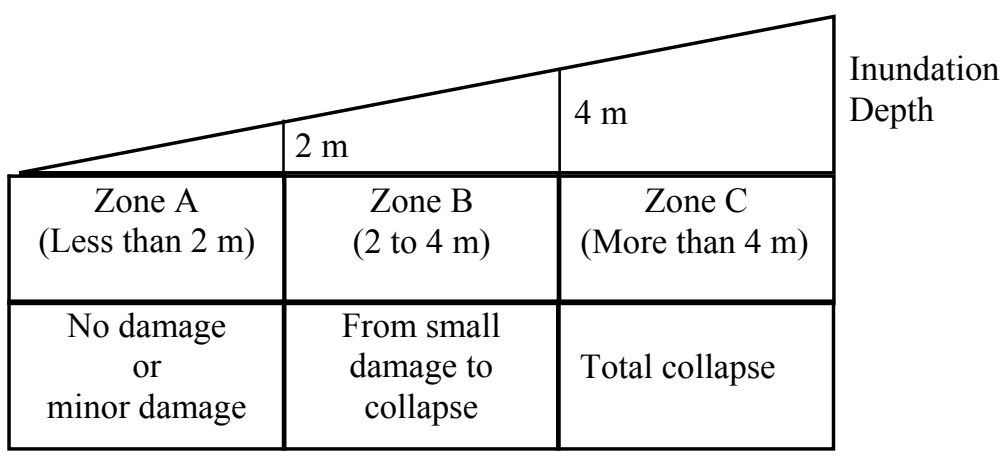

Figure 4: Inundation depth and damage on wooden houses.

Figure 5 shows some typical damage on wooden houses that was produced by the tsunami. In Figure 5(a) from the wooden debris, it can be observed that houses were destroyed by the tsunami action. It can be also observed that houses located on high sites were not affected. In Figures 5(b) and 5(c) the first floor was destroyed by the tsunami and the upper parts of the houses were transported and then left by the tsunami in a different place from their original location. In the case of Figure 5(d) the tsunami destroyed the first floor and also produced the overturning of the remaining upper floor.
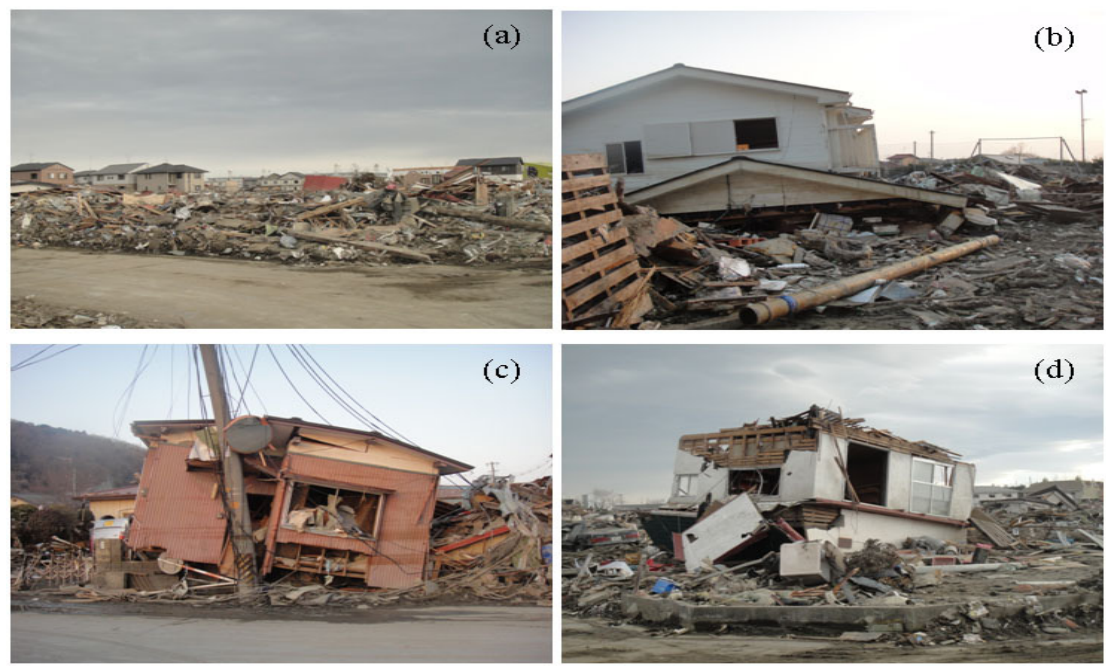

Figure 5: Damage on wooden houses.

\subsection{Damage on steel structures}

Steel structures are used in general for industrial facilities and office buildings. Most of the buildings are framed structures and structural elements like beams and columns are slender elements. Floors and walls are made of light panels and 
the lateral stiffness is appropriately designed to resist the earthquake force. However, during the tsunami attack the water pressure acting on panels or in general in elements of a large area generated large lateral forces that destroyed that non-structural elements and in some cases the failure of these elements led to the failure and even the collapse of the main structure.

Damage on steel structures can be observed in Figure 6. When the inundation depth reached only the first floor the structure remained almost intact; however, the wall panels of the first floor suffered some damage as can be observed in Figure 6(a). In Figures 6(b) and 6(c) the inundation depth reached the second floor and wall panels and ceiling were destroyed. In this case, the structures remained standing up; however, some local failure of the structural elements was observed. Figure 6(d) shows a total collapse of steel structures. In this case, the building was completely covered by water.
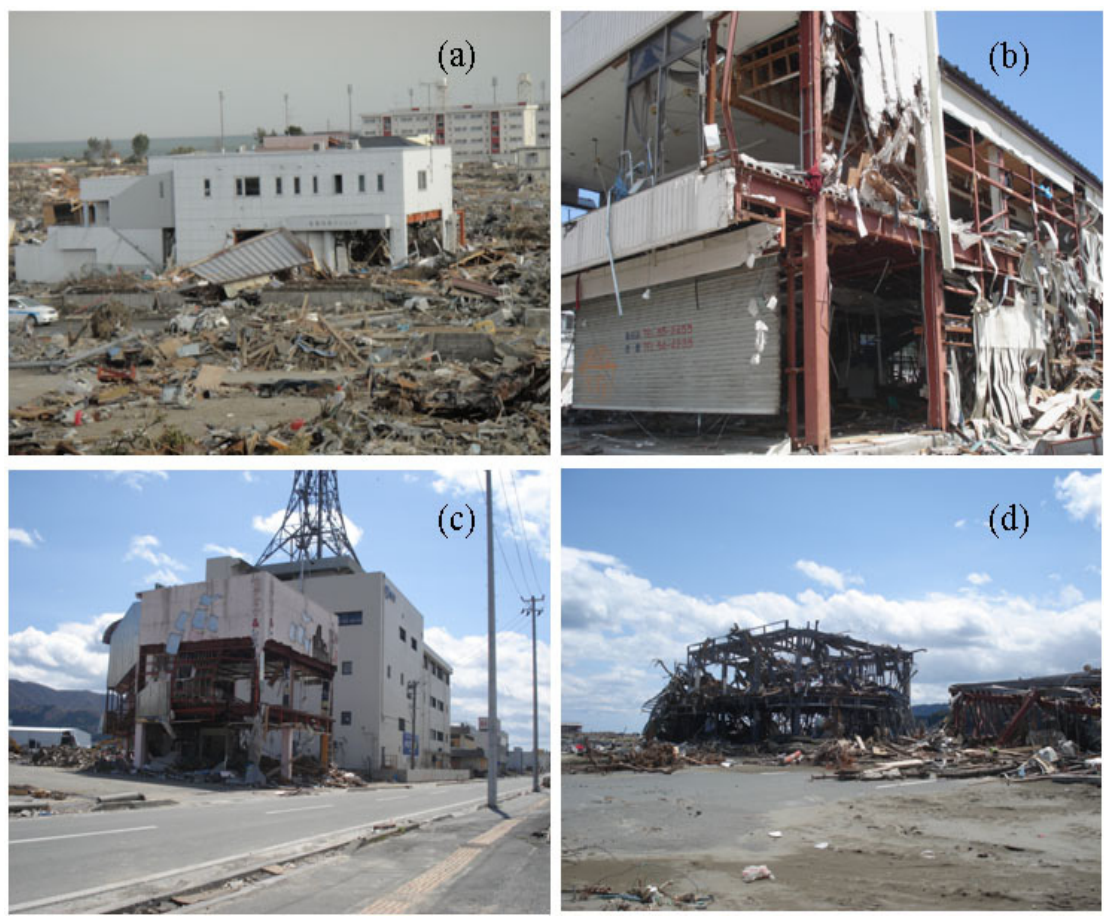

Figure 6: Damage on steel structures.

\subsection{Damage on RC structures}

Many reinforced concrete structures resisted the tsunami action without collapse as can be observed in Figure 7. Figure 7(a) is the building of a local bank located at Funato city, and it can be observed from the damage of the windows that the tsunami reached the second floor. In Figure 7(b) it is also inferred that the 
tsunami reached the second floor by observing that the window panes were destroyed and now are replaced by wooden panels. Figure 7(c) is an apartment building located at Rikusentakata city and, from the damage of the balconies, it is inferred that the tsunami reached the fourth floor. Figure 7(d) shows the condition of a hotel building located very near the shoreline. The building resisted the tsunami attack; however, the lower floors suffered the destruction of the non-structural elements and also, as can be observed in the figure, there was damage of a reinforced concrete wall due to the lateral water pressure. In this building it was also observed that the cover concrete of structural elements that columns spilled out, probably due to a combination of earthquake vibration action and posterior tsunami.
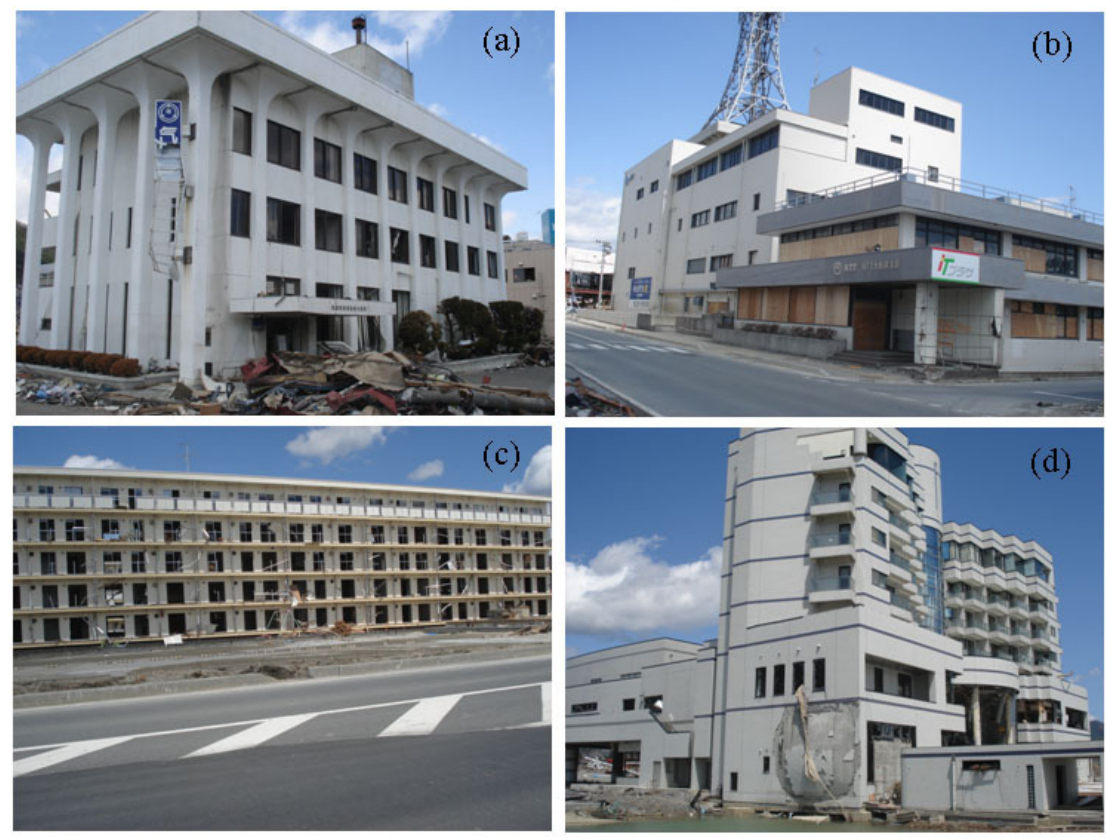

Figure 7: $\quad$ RC buildings after tsunami attack.

In general, reinforced concrete buildings did not collapse; however, under certain conditions, the tsunami action caused the overturning and even transportation of the building from its original location. This is reported by a survey team of the Tohoku Branch of the Architectural Institute of Japan [3]. This damage occurred at Onagawa town and the affected buildings were buildings with weak foundations, and with shapes like boxes that do not permit the transit of the water and facilitate the action of the floating force. In Figure 8 damage of these buildings, presented by the Japanese Broadcasting Television (NHK), is shown. 


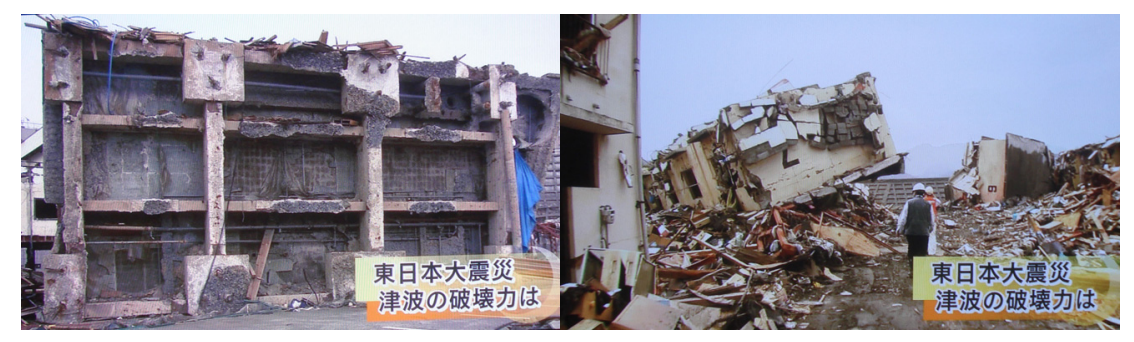

Figure 8: Damage on reinforced concrete buildings.

\section{Conclusions}

The behaviour of reinforced concrete buildings during the tsunami action originated by the Great East Japan Earthquake on March 11, 2011 was discussed by comparing their damage with those of other types of constructions. Reinforced concrete buildings, in general, resist the tsunami without collapse however, when constructions present shallow or weak foundations and building shapes induce the action of the floating force, overturning of the buildings was observed. In the case of non-collapsed buildings, severe damage on nonstructural elements like panels and ceilings was observed.

The survey has permitted us to understand the behaviour of reinforced concrete buildings under tsunami attack and it can be stated that these kinds of buildings could be used to take refuge from tsunami in places where natural topography makes it impossible to reach hilltops or other safer places.

\section{References}

[1] Shimizu Corporation. Report on the Tohoku Area Pacific Offshore Earthquake. http://www.shimz.co.jp/english/theme/earthquake/outline.html, 2011.

[2] Building Research Institute, Ministry of Construction of Japan, survey team. Quick Report on the Tohoku Area Pacific Offshore Earthquake (in Japanese), 2011.

[3] Tohoku Branch of the Architectural Institute of Japan. Quick report of Tsunami damage at Onagawa town. March 29, 2011.

[4] Yushiro Fujii, Kenji Satake, Shin-ichi Sakai, Masanao Shinohara and Toshihiko Kanazawa. Tsunami source of the 2011 off the Pacific coast of Tohoku, Japan earthquake Report of the International Institute of Seismology and Earthquake Engineering (IISEE),Building Research Institute (BRI). 2011.

[5] Akenori Shibata. An Overview of the 2011 Tohoku Earthquake and Tsunami. Presented at ROSE School Seminar, University of Pavia, Italy, May 192011. 
[6] K. Sugiyama, C. H. Cuadra and Y. Fujiwara. Characteristics of peak acceleration and attenuation during the 2008 Iwate-Miyagi earthquake. Proceedings of the $14^{\text {th }}$ European Conference on Earthquake Engineering, August 30-September 3, 2010, Ohrid, Macedonia.

[7] Cuadra, C. and Tokeshi, J. Lessons learned from the 2007 Pisco earthquake (Peru) and recommendations for disaster mitigation. Proceedings of the 14thWorld Conference on Earthquake Engineering, October 12-17, 2008, Beijing, China.

[8] A. Gupta and B.M. McDonald. Performance of building structures during the October 15, 2006 Hawaii earthquake. Proceedings of the 14thWorld Conference on Earthquake Engineering, October 12-17, 2008, Beijing, China.

[9] Kanai, J., Tokeshi, K., Cuadra, C., \& Karkee. M.B. Vibration characteristics of buildings using microtremor measurements. First European Conference on Earthquake Engineering and Seismology (a joint event of the $13^{\text {th }}$ ECEE and $30^{\text {th }}$ General Assembly of the ESC), Geneva, Switzerland, 3-8 September 2006, Paper Number: 708.

[10] Sunuwar, L., Karkee, M., Tokeshi, J., and Cuadra, C. Applications of GIS in Probabilistic Seismic Hazard Analysis of Urban Areas. Proceedings of the Fourth International Conference of Earthquake Engineering and Seismology, Tehran, Iran, 2003. 